\title{
Significance of terrestrial inflows to carbon and nitrogen distribution in the Lake Victoria surface water
}

\author{
Clavery TUNGARAZA ${ }^{1 *}$, Rubhera MATO ${ }^{2}$, Stelyus L. MKOMA ${ }^{1}$ and \\ Charles Nyarongo EZEKIEL ${ }^{3}$
}

\author{
${ }^{I}$ Department of Physical Sciences, Sokoine University of Agriculture, P.O Box 3038, Morogoro, Tanzania. \\ ${ }^{2}$ School of Environmental Science and Technology, Ardhi University, P.O Box P.O. Box 35176, Dar es Salaam, \\ Tanzania. \\ ${ }^{3}$ Tanzania Fisheries Institute, P.O Box 475, Mwanza, Tanzania. \\ *Corresponding author, E-mail: tungaraza@suanet.ac.tz,tungarazac@yahoo.co.uk; \\ Tel./Fax: +255-23-2603404, Tel: +255-713-283353
}

\begin{abstract}
This was an investigation to characterize seasonal and spatial distribution of particulate organic matter (POM) in the surface water of Lake Victoria at Speke Gulf, by using carbon-13 and nitrogen-15 isotopic signatures. Speke Gulf is under the influence of terrestrial inflow through river Simiyu. The POM from the lake surface water had higher $\mathrm{C}: \mathrm{N}$ ratio values decreasing towards the deeper lake water, an indication of decreasing nitrogen content relative to carbonic materials. Samples away from the river mouth provided C:N ratios within the Redfield ratio range (C:N:P; 106:16:1) indicating materials of phytoplanktonic origin. The POM isotopes composition indicated a maximum $\delta^{13} \mathrm{C}$ value of $-21.2 \%$ close to the river mouth and lowest value $(\sim-25 \%$ o away from the river influence. The $\delta^{15} \mathrm{~N}$ maximum (14.7\%o) was observed near the river mouth with lower values $\left(5.8 \%\right.$ ) found in deeper waters away from the river mouth. Overall, there was a general decrease of ${ }^{13} \mathrm{C}$ and $\delta^{15} \mathrm{~N}$ values from shallow water to deeper water. There was higher $\delta^{15} \mathrm{~N}$ value dispersion (std. Dev. $\pm 3.4 \%$ ) compared to $\delta^{13} \mathrm{C}$ values with std. Dev. $\pm 1.2 \%$. These values also varied with seasons, a phenomenon showing significant influence of land run off on the lake elemental distribution, carbon and nitrogen in particular.
\end{abstract}

(c) 2011 International Formulae Group. All rights reserved.

Keywords: Lake Victoria, Particulate Organic Matter, carbon and nitrogen, isotope signatures

\section{INTRODUCTION}

In natural ecosystems the transfer of organic matter from one reservoir to another is an important way for both element and energy transfer, this helps to supplement deficits to where there are insufficient. This observation also applies to the importance of exogenous organic matter input which subsidizes endogenous nitrogen and carbon deficit in different ecosystems. However, the availability of endogenous and exogenous elements in any ecosystem is understood to be dependent on the utilization (internal cycling) and transfer rates of ecosystems as exogenous carbon has been thought to bring about various negative consequences to ecosystems including consequences on population dynamics, predator-prey relationships and ecosystem processes (Polis et al., 1997). Also, it has been cited that exogenous inputs provide resources that may enhance consumer abundance beyond levels supported by

(C) 2011 International Formulae Group. All rights reserved. 
within-system primary production (Nakano and Murakami, 2001). In general the exogenous elements have been identified to affect the cycling of elements in another ecosystem. Another example of such elements is nitrogen which has been reported to inhibit some activities of decomposers in ecosystem especially when it is continuously flowing (Aber and Melillo, 1980). These changes may cause disturbances resulting to negative effects on the cycling ability of various elements in aquatic ecosystem.

The terrestrial and aquatic environments are typical examples of ecosystems portraying interactions which involve elemental transfers and this is the most extensively explored ecosystem interactions both in freshwater and marine environment. Whereas marine-terrestrial interactions have been dominated by the significance of mangrove ecosystem in the cycling of elements (Fleming et al., 1990; Dehairs, et al., 2000; Bouillon, et al., 2002). Freshwater-terrestrial interactions are diverse due to different plant colonisation along river systems (De Brabandere et al., 2002; Cloern et al., 2002; Lawson, et al., 2004; Pace et al., 2004). For large water bodies like the Lake Victoria, such interactions are similarly diverse and the movement and cycling of elements influence the biological communities of the lake and need to be explored. Given the importance of carbon and nitrogen in the aquatic productivity, it is important to understand their movement and interaction among different ecosystems.

In recent years, the Lake Victoria environment has indicated deterioration characteristics. Observations have indicated appearance of massive blooms of algae dominated by the potentially toxic blue-green species (Sekadende, et al., 2005) and water transparency index has been reported declining from five meters in the early $1930 \mathrm{~s}$ to one meter or even less for most of the years in the early 1990's (Klohn and Andjelic, Online). These changes are causing other secondary impacts to the lake environment like the increase of water-borne diseases frequency due to water quality deterioration (Lung'ayia, et al., 2001). In aquatic environments, these changes are mainly controlled by carbon and nitrogen which are the major elements controlling primary productivity. Similarly, in Lake Victoria, the two elements have been assessed for their importance in supporting the lake's productivity (Gichuki et al., 2001; 2005). The two elements are transported in form of particulate organic matter (POM) and dissolved forms, depending on biological processes taking place before reaching the lake. The above environmental changes which are observed in the Lake Victoria are biological responses resulting from various physical and chemical changes, but there have been limited investigations to explain these phenomena and especially how seasonal and spatial composition changes of the two important elements in the lake ( $\mathrm{C}$ and $\mathrm{N}$ ) are connected to the observed biological responses.

In this study, stable isotopes composition in suspended particulate matter (SPM) was used to establish temporal and spatial distribution of carbon and nitrogen. The interaction of these two elements between terrestrial and the Lake Victoria were explored by comparing sampled SPM from different points of the lake water. This is an investigation based on the isotopic ratio (signature) concept which has been used to establish the origin of biogeochemical material in various systems (Ostrom et al., 1997; McClelland and Valiela, 1998; Riera et al., 2000) in relation to their carbon pathways. For example, Fry and Sherr (1984) reported that vascular plants using the $\mathrm{C} 3$ photosynthetic pathway have $\delta^{13} \mathrm{C}$ between $31 \%$ and $-26 \%$ o) whereas $\mathrm{C} 4$ salt marsh plants ratio is between $-16 \%$ to $-12 \%$ o). Oceanic phytoplankton are reported to have intermediate $\delta^{13} \mathrm{C}$ values close to $-21 \%$. Carbon and nitrogen ratios $\left(\delta^{13} \mathrm{C}\right.$ and $\left.\delta^{15} \mathrm{~N}\right)$ values in the lake environment can as well be used to indicate the origin of organic material. The ratios were therefore used to present the 
differentiation and interactions of the two ecosystems, Lake Victoria and Simiyu River by comparing two elements, carbon and nitrogen isotopic signatures of the organic matter sampled from the lake surface water. Simiyu River is one of the important river systems in the Tanzanian part of Lake Victoria. Like many other river systems of the Lake Victoria region, the river basin has been under agricultural activities (Scheren, et al., 2000; Tamatama, 2004) which have systematically affected its smooth water flow to the Speke Gulf of Lake Victoria. This has an effect to the riverine elemental fluxe as more particulate matter resulting from these activities are being transported. We explored seasonal and spatial distribution of the organic material in the lake surface water and present possible effects to the elemental distribution in the lake.

\section{MATERIALS AND METHODS}

Study area and sampling

Samples for this study were collected from Speke Gulf, receiving terrestrial inflow from Simiyu River. Simiyu river originates from a vast catchment area of about 10,800 $\mathrm{km}^{2}$ (Rwetabula and De Smedt, 2005) with tributaries forming a single entry to Lake Victoria (Figure 1). Personal communication to local people explains that in the past, the Simiyu River maintained notable annual water flow however, the current situation observed during this study, showed reduced and stagnant water pools during dry months of the year (June - August) and significant water discharge only during the rainy season (March - May). This is explained to be associated with agricultural activities being undertaken along the river basin and reduced rainfall in the region due to climatic changes in the region (Swenson and Wahr, 2009; Awange et al., 2007; 2008).

Sampling of surface Lake water was done during periods of high runoff (MarchApril) and periods of low runoff (June August) in 2007 - 2009. Fifteen sampling stations were selected along a straight transect from the river mouth (Figure 1) at a distance interval of approximately 100 meters. The coordinates of each station were recorded for reference purposes during sampling. All samples were taken using plastic containers then filtered for recovering suspend particulate matter (SPM) on precombusted (at $450{ }^{\circ} \mathrm{C}$ for 8 hours) $\mathrm{GF} / \mathrm{F}$ filter paper which was used for determination of $\mathrm{C}: \mathrm{N}$ ratios.

\section{Determination of $\mathrm{C}$ to $\mathrm{N}$ ratios}

The elemental ratios of carbon and nitrogen $(\mathrm{C}: \mathrm{N})$ were computed from the particulate organic carbon and the particulate organic nitrogen (POC and PON) analyses values using a Carlo Erba NA $1500 \mathrm{C} / \mathrm{N}$ analyser (Pella, 1991). The suspended particulate organic matter from the water sample collected by filtration explained above were dried at $50{ }^{\circ} \mathrm{C}$ oven temperature for 24 hours followed by acid fumes $(\mathrm{HCl})$ treatment of the sample to eliminate inorganic contaminants. Samples were then enclosed in tin cups before the combustion process which led to the production of carbon dioxide and nitrogen gases, simultaneously. The separation of carbon dioxide and nitrogen gases was done by a gas chromatographic column (Porapak QS) and measured by thermal conductivity which are all integrated in the analytical machine ( $\mathrm{C} / \mathrm{N}$ analyser).

\section{Isotopic composition analyses}

Isotopic ratios were calculated from isotope compositions of samples which were analysed by mass spectrometric method using a Delta E Finnigan Mat dual inlet isotope ratio mass spectrometer. The ratio calculations were developed by comparison with standard samples for the two isotopes, which were ammonium sulphate for nitrogen standards and glucose for carbon standards all treated in similar manners as the samples explained before. Values were expressed relative to Vienna Peedee Belemnite standard (VPDB). A classical method for $\delta^{15} \mathrm{~N}$ values establishment was by expressing its values relative to atmospheric $\mathrm{N}_{2}$ reference. Repeated 
analyses of five standard samples resulted into a standard deviation of $\pm 0.38 \%$ o for nitrogen and $\pm 1.52 \%$ o for carbon which was well within acceptable range of reproducibility in comparison to the sample values.

\section{RESULTS}

The difference in the isotopic signatures shown in Figure 2 differentiates two environments: one dominated by organic materials of terrestrial origin and the other dominated by those internally generated, i.e. of phytoplankton origin as was observed during low runoff season. It was observed that the isotopic ratios of carbon and nitrogen (i.e. $\delta^{13} \mathrm{C}$ and $\left.\delta^{15} \mathrm{~N}\right)$ increased towards the river mouth implying that the values decreased from shallow water, close to the river mouth to deeper water, away from the river mouth influence (Figure 2). The results indicated a maximum $\delta^{13} \mathrm{C}$ value of $-21.2 \%( \pm 0.05 \%$ o $)$ and a minimum value of $-25.0 \%$ o $( \pm 0.09 \%$ ) . Meanwhile, the maximum $\delta^{15} \mathrm{~N}$ value was $14.7 \%$ o $( \pm 0.41 \%$ o $)$ whereas the minimum value was about $5.8 \%$ o $( \pm 0.8 \%$ o). Obviously, samples from the river mouth had more signals of terrestrial organic matter compared to samples from deeper water. In other words, the indication is that organic matter of terrestrial origin have significantly higher $\delta^{13} \mathrm{C}$ and $\delta^{15} \mathrm{~N}$ values compared to those internally generated organic matter (of phytoplankton origin).

The differentiation of composition was also done by establishing the $\mathrm{C}: \mathrm{N}$ ratio values of samples for the two different seasons (rainy season and dry season). The results indicate that the ratio values were generally decreasing from the river mouth to deeper water (Figure 3). During high runoff, the sampling station 1 (at the river mouth) recorded ratio value of 19 and decreased to 18.7 at station 2 . The ratio decrease continued to 17 and 16 between station 3 and 4. A slight increase was observed at station 5 but the general trend was decreasing reaching a minimum value of about 10 at sampling station 15, in deeper water. Similar trend was observed during low runoff (dry season) where from the river mouth the highest ratio value observed was 19.6, slightly higher than that of samples during high runoff. Again, the ratio showed a decrease towards deeper water and the lowest ratio value observed at station 15 was about 7 , a value lower than the lowest value observed during high runoff.

Although there were similarities in the ratio trend, one significant difference is the slow decrease of the ratio values which were observed during high runoff period. It is observed that during high runoff, samples from stations 6 to 12 showed values that were above the Redfield range of $6-12$ (commonly accepted range; Figure 3). This trend continued and only sampling stations 13 to 15 showed values within the Redfield ratio. A different observation was made during low runoff season, samples from station $9-15$ were within the Redfield range. This was a notable difference implying that during low runoff, phytoplanktonic organic matter appeared close to the river mouth compared to the situation observed during high runoff season.

The isotopic ratio values shown in Figure 4 give a close relationship of the two ratio values during high runoff and low runoff seasons. The high runoff season showed $\delta^{13} \mathrm{C}$ variation from $-23.3 \%$ (the lowest) to $-22.01 \%$ (the highest), whereas the $\delta^{15} \mathrm{~N}$ of the same suspended organic matter varied between $9.5 \%$ and $16.1 \%$. Similar observations made during low runoff indicated a variation ranging between $-23.8 \%$ o and $-21.8 \%$ for $\delta^{13} \mathrm{C}-\mathrm{SPOM}$ and between $6.0 \%$ and $12.3 \%$ for $\delta^{15} \mathrm{~N}-\mathrm{SPOM}$. The major difference, however, of the two figures (Figure 4a and b) is observed on the trends and distribution of isotopic ratio values. High runoff ratios indicated low dispersion between 8 and 16 ratio values whereas low runoff ratios dispersion appeared between $\sim 4$ and 12 . Although there was seasonal variations of the isotopic ratios, the dispersion of $\delta^{15} \mathrm{~N}$ values was higher (std. Dev. $\pm 3.4 \%$ ) compared with that of $\delta^{13} \mathrm{C}$ values (std. Dev. $\pm 1.2 \%$ ). 


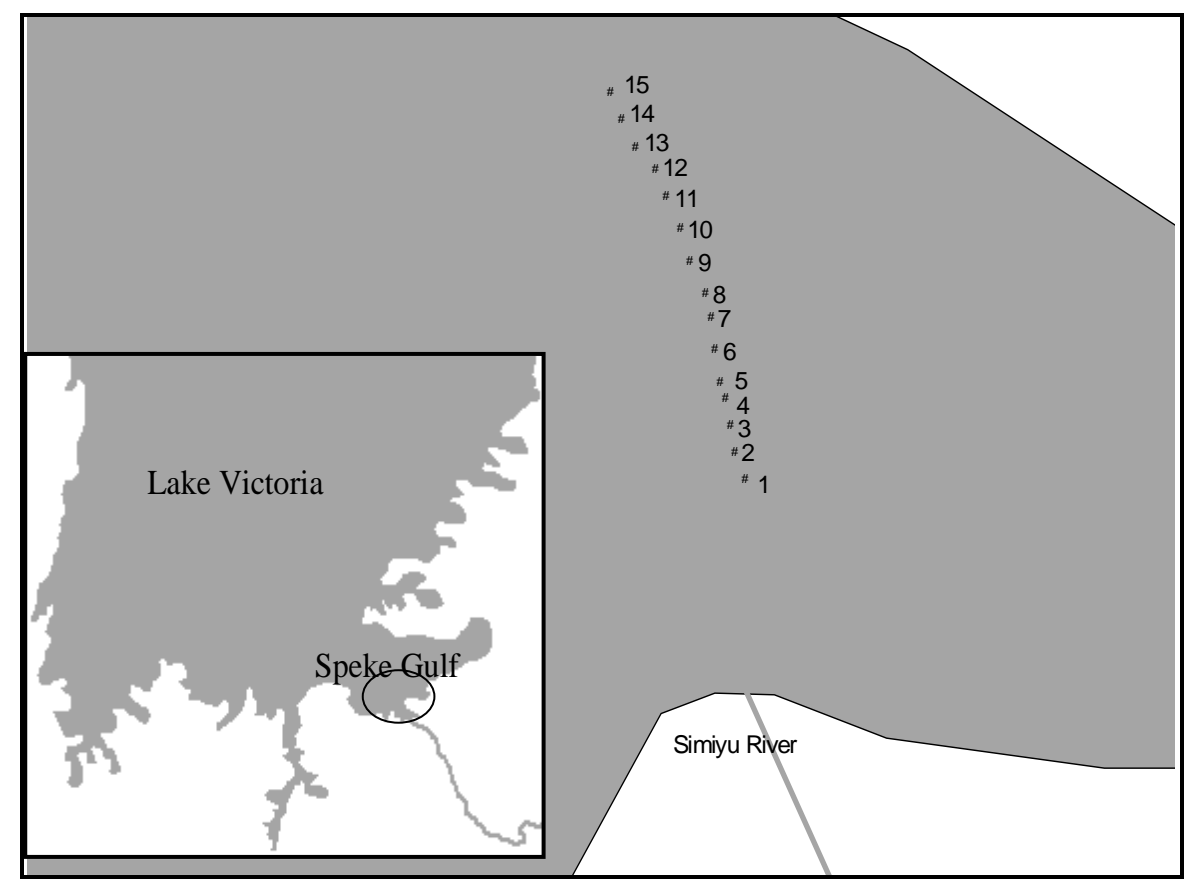

Figure 1: Sampling stations at Speke Gulf (station 1 -15) in Lake Victoria. The number indicates the sequential arrangement of the direction of sampling transect.

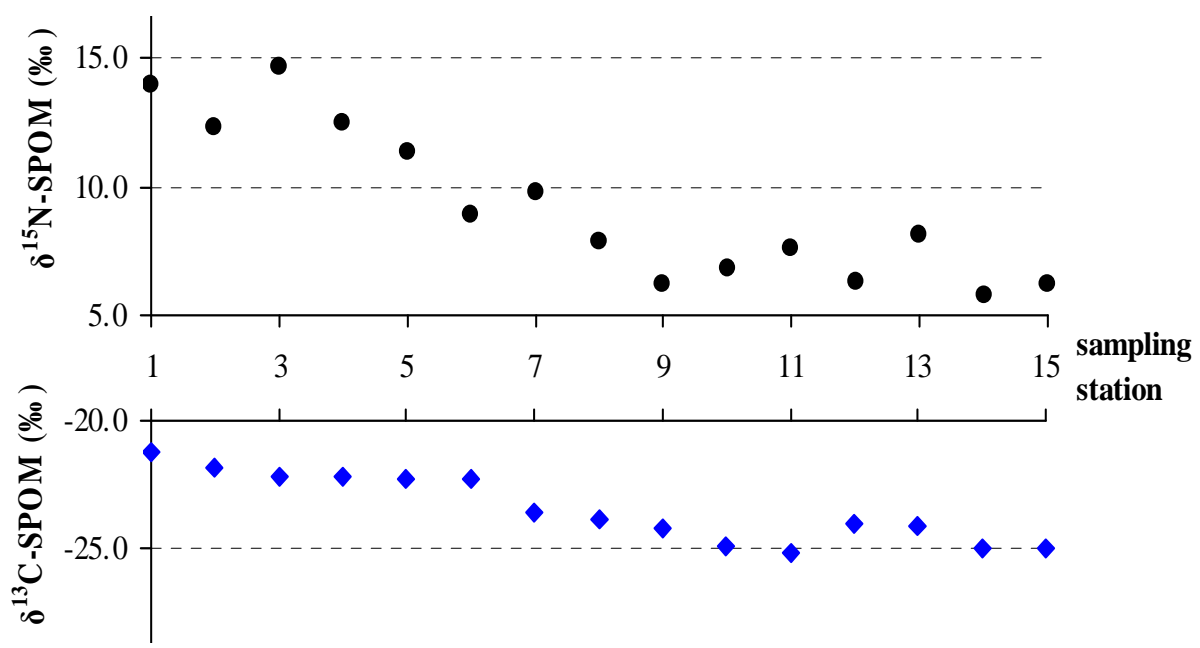

Figure 2: Variations in $\delta^{13} \mathrm{C}$ and $\delta^{15} \mathrm{~N}$ of suspended particulate organic matter (SPOM) from the Lake Victoria surface water.

Showing simultaneous decrease of isotope enrichment from shallow water of the Lake (near to the river mouth station 1) to deeper water (station 15). 


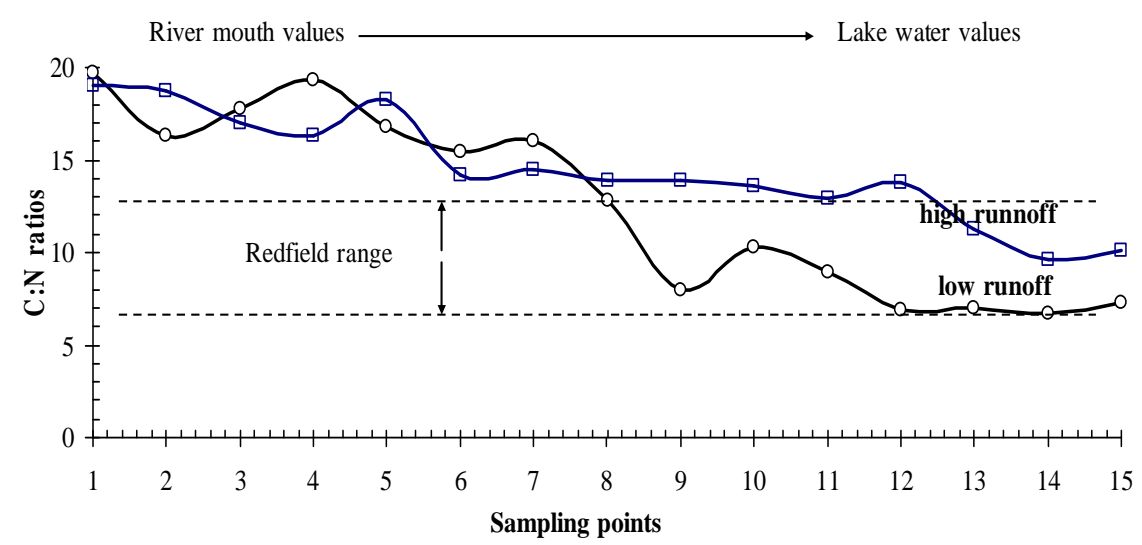

Figure 3: Molecular ratios of carbon to nitrogen of particulate organic matter samples during high and low runoff seasons from the river mouth (Simiyu river) to deeper water of the Lake Victoria. Dotted lines indicate expected range of ratios (Redfield ratio) for samples dominated by phytoplanktonic materials.
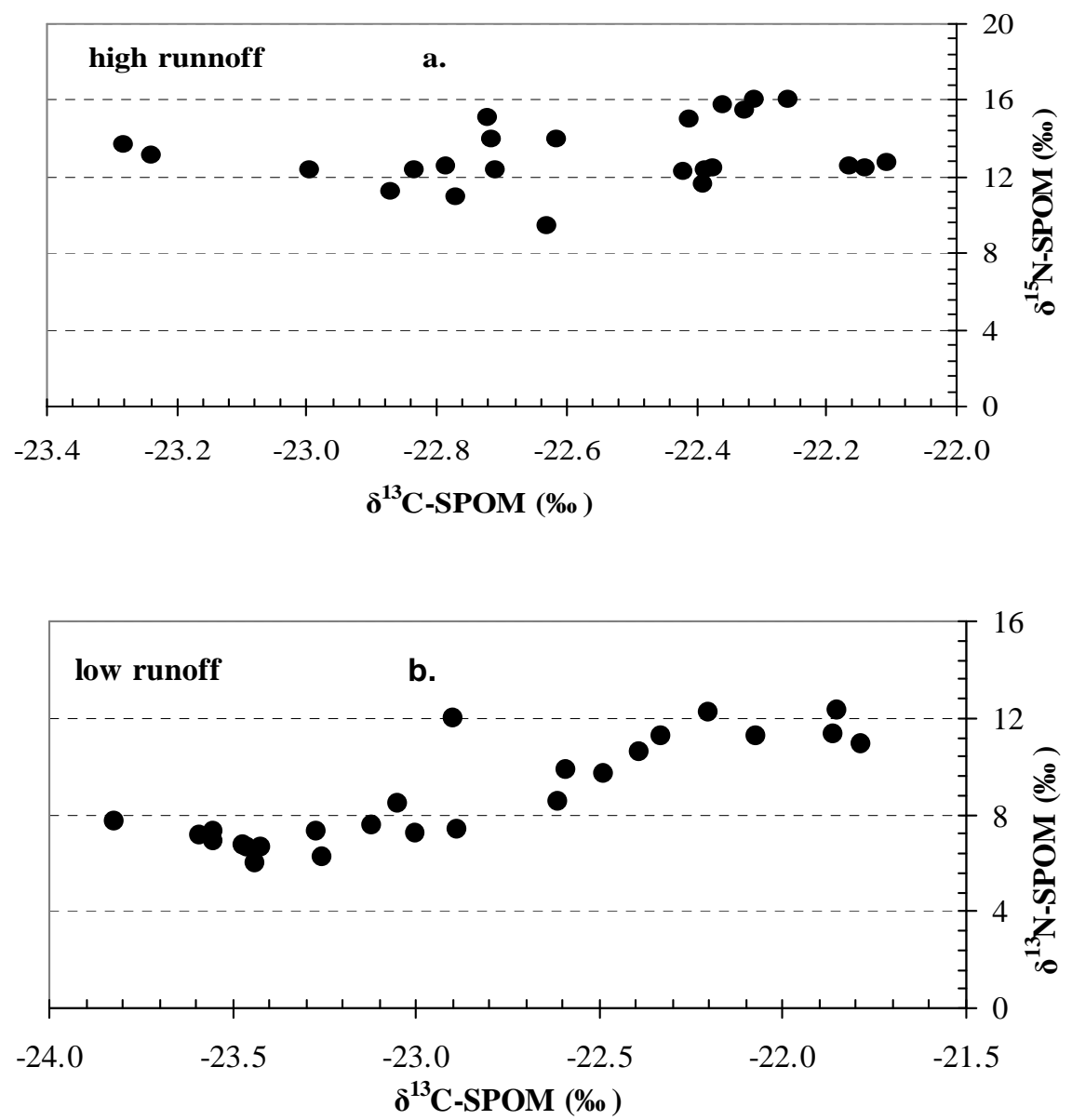

Figure 4: Isotope ratios relationship $\left(\delta^{15} \mathrm{~N}\right.$ vs. $\left.\delta^{13} \mathrm{C}\right)$ of suspended organic matter (SPOM) observed during high runoff (a) and low runoff (b) of the Speke Gulf. 


\section{DISCUSSION}

The results indicate that the organic particulate matter of terrestrial origin has higher $\delta^{13} \mathrm{C}$ and $\delta^{15} \mathrm{~N}$ values compared with that of lake water origin (internally generated). The isotopic ratios of carbon and nitrogen have shown variation from shallow water to deeper water, which is considered to be as a result of differences in the isotopic composition of particulate matter from terrestrial environment and that internally generated lake organic materials. These emphasise the differences between the two sources of elements as has been indicated above. With this observation, the pertinent question is on the consequences of such inputs especially as it has been raised by some authors cited herein above (Polis et al., 1997; Nakano and Murakami, 2001; Aber and Melillo, 1980). The isotopic composition clearly shows the difference of the two environment (terrestrial and Lake Victoria aquatic environment) although are constantly mixing-up through river flow. From the isotopic ratios, it is clear that the lake biological ecosystem eventually segregates itself to regain the biologically natural atomic ratio as observed from the $\mathrm{C}: \mathrm{N}$ ratios of the organic particulate matter in Figure 3.

The use of isotopic ratios has shown that, phytoplankton materials have lower values of $\delta^{13} \mathrm{C}$ and $\delta^{15} \mathrm{~N}$ compared to nonphytoplanktonic materials as is shown in Figure 4, where the surface water $\delta^{13} \mathrm{C}$ values of suspended organic matter were as low as $-23.8 \%$ during low runoff (season of phytoplankton dominance) whereas the lower value during high runoff was $-23.2 \%$. This difference is maintained and more elaborated by $\delta^{15} \mathrm{~N}$ which provided a highest value of $16.0 \%$ during high runoff season compared to $12.3 \%$ during low runoff season. It is therefore notable that during high runoff the gulf was dominated by materials of terrestrial origin as was also presented by Machiwa, (2010), linking the dominance of Phragmite sp. in the gulf to the $\mathrm{C}-13$ value. The dominance of terrestrial material was low during low runoff season and the two scenarios are differentiated by the Redfield ratio. Our interpretation indicates that the Simiyu river basin and the particulate matter characteristics cannot be ascribed to a single species of plant rather to diverse type of natural vegetation and agricultural crops. This provided different isotope ratios with season. The Redfield ratio indicates that only stations 13 to 15 during high runoff were within the acceptable range whereas during low runoff stations 8 to 15 all provided the $\mathrm{C}: \mathrm{N}$ ratio values within the range.

The abundance of phytoplanktonic organic matter away from the river mouth compared to water close to the river mouth can be interpreted to be a result of the current understanding that probably phytoplankton communities cannot easily assimilate the available exogenous elemental materials (Wetzel, 1995; Cyr and Pace, 1993). However, alternatively water turbidity may be one of the major factors affecting the distribution of phytoplankton by affecting light penetration and therefore poor phytoplankton growth near the river mouth. This problem is exaggerated during high runoff as the river input and turbidity reaches deeper water diluting the dominance of phytoplanktonic organic matter in the area despite the possible high nutrient availability, which is a characteristic at all areas under river flow influence. The ecological impacts under such scenario can be extended to biological productivity of the lake since conditions like light penetration may become a limiting factor and consequently carbon and nitrogen distribution in the lake. It is similarly important to note from the distribution that terrestrial input may actually affect the lake environment since the biological communities (the phytoplankton) are always at their natural $\mathrm{C}: \mathrm{N}$ ratio (Redfield ratio). This implies that constant input of exogenous matter becomes 
useful only when there is enough time for other biological processes like mineralization to take place. However, it is important to note that excessive input of organic materials is likely to destabilize the gulf ecology due to higher availability and stability of carbon in organic matter. This is not the case for nitrogen which is highly labile in aquatic environment and because of that, it is showing higher variation as exemplified by the standard deviation.

\section{Conclusion}

From these observations, we can conclude that, there is an obvious diversity of isotopic signatures of both carbon and nitrogen with seasons which implies that Lake Victoria organic matter input at Speke Gulf follows the intensity of river discharge and consequently, on the composition variation of the riverine materials. This makes necessary to monitor activities undertaken in the river basin. As supported by literature, Simiyu River basin is increasingly subjected to agricultural activities which subsequently influence the nature and type of organic matter being transported. This condition needs to be abated by limiting agricultural activities in the basin which seem to exacerbate the organic matter inflow problem. The traditional known advantage of river flow which brings nutrients and carbon sources from terrestrial environment is important to be monitored. However, this study shows that not all elements can be of similar use in the environment. Here carbon is shown to be resistant with long resident time than nitrogen therefore conservation of environment is necessary so as to enhance biological activities which are necessary in managing these elements especially the most labile like nitrogen. Apart from these two monitored elements (carbon and nitrogen) there, it is necessary to undertake more investigations on other inputs of elements especially agriculture-associated pollutants which are likely to be highly affecting this environment and other parts of the lake. This subject needs further investigation so as to understand the kinetics of elements from different sources including atmospheric depositions, which are all considered exogenous in the aquatic environment.

\section{ACKNOWLEDGEMENTS}

This work was supported by the International Atomic Energy Agency (IAEA), under research programme "Isotopic techniques for assessment of hydrological processes in wetlands". We acknowledge support from the Tanzania Fisheries Research Institute (TAFIRI). Our appreciation to Dr Natacha Brion and Prof. Willy Baeyens of the Laboratory of Analytical and Environmental Chemistry (ANCH), Vrije Universiteit Brussel for facilitating sample analysis.

\section{REFERENCES}

Aber JD, Melillo JM. 1980. Litter decomposition: measuring relative contributions of organic matter and nitrogen to forest soils. Can. J. Bot., $\mathbf{5 8}$ : 416-421.

Awange JL, Ogalo L, Bae K, Were P, Omondi P, Omute P, Omullo M. 2008. Falling Lake Victoria water levels: Is climate a contributing factor? Clim Change, 89: 281-297.

Awange JL, Aluoch J, Ogallo LA, Omulo M, Omondi P. 2007. Frequency and severity of drought in the LakeVictoria region (Kenya) and its effects on food security. Clim Res., 33: 135-142.

Bouillon S, Raman AV, Dauby P, Dehairs F. 2002. Carbon and Nitrogen Stable Isotope Ratios of Subtidal Benthic Invertebrates in an Estuarine Mangrove Ecosystem (Andhra Pradesh, India). Est. Coast. Shelf Sci., 54: 901-913.

Cloern JE, Canuel EA, Harris D. 2002. Stable carbon and nitrogen isotope composition 
of aquatic and terrestrial plants of the San Francisco Bay estuarine system. Limnol. Oceanogr., 47(3): 713-729.

Cyr H, Pace ML. 1993. Magnitude and patterns of herbivory in aquatic and terrestrial ecosystems. Nature, 361: 148150.

De Brabandere L, Dehairs F, Van Damme S, Brion N, Meire P, Daro N. 2002. $\delta^{15} \mathrm{~N}$ and $\delta^{13} \mathrm{C}$ dynamics of suspended organic matter in freshwater and brackish waters of the Scheldt estuary. J. Sea Res., 48: 115.

Dehairs F, Rao RG, Chandra MP, Raman V, Marguillier S, Hellings L. 2000. Tracing mangrove carbon in suspended matter and aquatic fauna of the Gautami-Godavari Delta, Bay of Bengal (India). Hydrobiologia, 431: 225-241.

Fleming M, Lin G, Sternberg SL. 1990. Influence of mangrove detritus in an estuarine ecosystem. Bull. Mar. Sci., 47: 663-669.

Gichuki J, Triest L, Dehairs F. 2001. The use of stable carbon isotopes as tracers of ecosystem functioning in contrasting wetland ecosystems of Lake Victoria, Kenya. Hydrobiologia, 458: 91-97.

Gichuki J, Triest L, Dehairs F. 2005. The fate of organic matter in a papyrus (Cyperus papyrus L.) dominated tropical wetland ecosystem in Nyanza Gulf (Lake Victoria, Kenya) inferred from $\delta^{13} \mathrm{C}$ and $\delta^{15} \mathrm{~N}$ analysis. Isotopes Environ. Health Stud., 41(4): 379-390.

Klohn W, Andjelic M. Lake Victoria: A Case in International Cooperation. Online: http://www.fao.org/ag/AGL/AGLW/web pub/Lakevic/LAKEVIC4.htm (accessed on January 2007).

Lawson J, Doran PT, Kenig F, Des Marais DJ, Priscu JC. 2004. Stable Carbon and Nitrogen Isotopic Composition of Benthic and Pelagic Organic Matter in Lakes of the McMurdo Dry Valleys. Antarctica Aquatic Geochem., 10: 269-301.
Lung'ayia H, Sitoki L, Kenyanya M. 2001. The nutrient enrichment of Lake Victoria (Kenyan waters). Hydrobiologia, 458(13): 75-82.

Machiwa JF. 2010. Stable carbon and nitrogen isotopic signatures of organic matter sources in near-shore areas of Lake Victoria, East Africa. Journal of Great Lakes Research, 36: 1-8.

McClelland JW, Valiela I. 1998. Changes in food web structure under the influence of increased anthropogenic nitrogen inputs to estuaries. Mar. Ecol. Prog. Ser., 168: 259- 271.

Nakano S, Murakami M. 2001. Reciprocal subsidies: dynamic interdependence between terrestrial and aquatic food webs. Proc. Natl Acad. Sci., 98: 166-170.

Ostrom NE, Macko SA, Deibel D, Thompson RJ. 1997. Seasonal variation in the stable carbon and nitrogen isotope biogeochemistry of a coastal cold ocean environment. Geochim. Cosmochim. Acta., 61: 2929- 2942.

Pace ML, Cole JJ, Carpenter SR, Kitchell JF, Hodgson JR, Van de Bogert MC, Bade DL, Kritzberg ES, Bastviken D. 2004. Whole-Lake carbon-13 additions reveal terrestrial support of aquatic food webs. Nature, 427(15): 240 - 243.

Polis GA., Anderson WB, Holt RD. 1997. Toward an integration of landscape and food web ecology: the dynamics of spatially subsidized food webs. Annu. Rev. Ecol. Syst., 28: 289-316.

Riera P, Stal LJ, Nieuwenhuize J. 2000. Heavy $\delta^{15} \mathrm{~N}$ in intertidal benthic algae and invertebrates in the Scheldt Estuary (The Netherlands): effect of river nitrogen inputs. Est. Coast. Shelf Sci., 51: 365372.

Rwetabula J, De Smedt F. 2005. Landuse and Land Cover Mapping of the Simiyu Catchment (Tanzania) Using Remote Sensing Techniques. From Pharaohs to 
Geoinformatics. FIG Working Week and GSDI-8 Cairo, Egypt April 16-21, 2005.

Scheren PAGM, Zanting HA, Lemmens AMC. 2000. Estimation of water pollution sources in Lake Victoria, East Africa: Application and elaboration of the rapid assessment methodology. J Environ Manage., 58: 235-248.

Sekadende BC, Lyimo TJ, Kurmayer R. 2005. Microcystin production by cyanobacteria in the Mwanza Gulf (Lake Victoria, Tanzania). Hydrobiologia, 299-304. 10.1007/s10750-004-6949-6.
Swenson S, Wahr J. 2009. Monitoring the water balance of Lake Victoria, East Africa, from space. J. Hydrol., 370: 163176.

Tamatama RA. 2004. Phosphorus sorption characteristics of sediment in the Simiyu and Kagera River basins: implications for phosphorus loading into Lake Victoria. Afr. J. Aquat. Sci., 29(2): 243-248.

Wetzel RG. 1995. Death, detritus, and energy flow in aquatic ecosystems. Freshw. Biol., 33: 83-89. 